Article

\title{
Evaluation of Direct Ultrasound-Assisted Extraction of Phenolic Compounds from Potato Peels
}

\author{
Shusheng Wang ${ }^{1,2}$, Amy Hui-Mei Lin ${ }^{3,+}$, Qingyou Han ${ }^{4}$ and Qin $\mathrm{Xu}^{2, *}$ \\ College of Life Science, Jilin Agricultural University, Changchun 130118, China; wangshusheng@jlau.edu.cn \\ Department of Food Science, Purdue University, W. Lafayette, IN 47907, USA \\ Bi-State School of Food Science, University of Idaho, Moscow, ID 83844, USA; amy_lin@sifbi.a-star.edu.sg \\ 4 School of Engineering Technology, Purdue University, W. Lafayette, IN 47907, USA; hanq@purdue.edu \\ * Correspondence: xuq@purdue.edu; Tel.: +1-765-494-4183 \\ + Present address: Clinical Nutrition Research Center, Singapore Institute of Food and Biotechnology \\ Innovation, Agency for Science, Research and Technology, Singapore 117609, Singapore.
}

Received: 16 November 2020; Accepted: 15 December 2020; Published: 17 December 2020

check for updates

\begin{abstract}
Potato peels (PPs) are generally considered as agriculture waste. The United States alone generates over one million tons of PPs a year. However, PPs contain valuable phenolic compounds with antioxidant activities. In this study, we evaluated the efficiency of ultrasound-assisted extraction techniques in recovering antioxidants from PPs. These techniques included a direct ultrasound-assisted extraction (DUAE), an indirect ultrasound-assisted extraction (IUAE), and a conventional shaking extraction (CSE). Results of this study showed that DUAE was more effective in extracting phenolic compounds than IUAE and CSE. We also evaluated the factors affecting the yield of total phenolic compounds (TPC) in DUAE, including the temperature, time, acoustic power, ratio of solvent to solids, and size of PPs particles. TPC yield of DUAE was higher, and the extraction rate was faster than IUAE and CSE. Furthermore, TPC yield was strongly correlated to the temperature of the mixture of PPs suspension. SEM images revealed that the irradiation of ultrasound energy from DUAE caused micro-fractures and the opening of PPs cells. The extract obtained from DUAE was found to have antioxidant activity comparable to commercial synthetic antioxidants. Results of this preliminary study suggest that DUAE has the potential to transform PPs from agricultural waste to a valuable ingredient. A future systematic research study is proposed to advance the knowledge of the impact of processing parameters in the kinetics of phenolic compounds extraction from potato peels using various extraction methods.
\end{abstract}

Keywords: potato peel; ultrasound; phenolic compound; antioxidant

\section{Introduction}

Potatoes (Solanum tuberosum L.), along with corn, rice, and wheat, are a staple food source [1], and its processed foods are popular globally. As most potatoes are peeled before processing, the United States alone generates over one million tons of potato peels yearly, creating disposal, sanitation, and environmental problems [2,3]. However, potato peels contain valuable substances such as phenolic compounds, which are natural antioxidants. On average, potato tubers contain $25-125 \mathrm{mg}$ of phenolic compounds per $100 \mathrm{~g}$ fresh weight, and approximately $50 \%$ of the phenolic compounds are in peels and adjoining tissues [4,5]. The primary phenolic compounds found in potatoes are chlorogenic acid, caffeic acid, p-coumaric acid, and ferulic acid [6,7]. Phenolic compounds in plants are involved in many physiological processes, such as cell growth, root formation, seed germination, and fruit ripening. Moreover, phenolic compounds can act as reducing agents, hydrogen donors, and scavengers of reactive oxygen species [8]. In addition to antioxidant activity, phenolic compounds have antidiabetic, 
anti-microbial, anti-allergy, vasodilation, and cardio-protective activities [9]. The food industry relies on synthetic antioxidants, such as butylated hydroxytoluene (BHT), butylated hydroxyanisole (BHA), and tert-butylhydroquinone (TBHQ) for preventing lipid oxidation [10]. However, synthetic antioxidants are associated with some health risks, such as hepatic damage and the development of cancers [11]. Therefore, there is a demand for natural antioxidants, for which potato peel extract is an ideal source.

Methods for the extraction of phenolic compounds can be categorized into conventional and novel methods. The conventional method requires a high quantity of organic solvents during solid-liquid interaction and a long extraction time with low yields [12-14]. Novel methods are more effective in extracting phenolic compounds. Novel methods include subcritical water extraction, microwave-assisted extraction, high-pressure homogenization extraction, pressured liquid extraction, and ultrasound-assisted extraction [15-17]. The ultrasound-assisted extraction methods have received considerable attention due to their high capability and efficiency of extraction [18]. In addition, the ultrasound-assisted extraction methods are simple, flexible, versatile, and economic [19].

The ultrasound-assisted extraction method can be further categorized into indirect ultrasound-assisted extraction (IUAE) using an ultrasound bath and direct ultrasound-assisted extraction (DUAE) using an ultrasound probe. IUAE has been tested for extracting phenolic compounds from potato peels; however, DUAE, which has much higher ultrasonic power density than that of IUAE, has not yet been examined for extracting phenolic compounds from potato peels. The high level of ultrasonic irradiation in DUAE can accelerate the extraction, but its impact on the production and antioxidant activity have not been investigated either. This study examined the extraction efficacy of the DUAE and compared it with that of both IUAE and CSE. The study also examined the antioxidant activity of the extract produced by DUAE and compared it with that of popular synthetic antioxidants. The long-term goal of this investigation was to efficiently process a large number of potato peels, which are otherwise wasted, and turn this waste product into a valuable commodity.

\section{Materials and Methods}

\subsection{Materials}

Potato peels were from Basic American Foods (Blackfoot, ID, USA). Peels were dried in a convection oven at $45^{\circ} \mathrm{C}$ for $48 \mathrm{~h}$. The dehydrated potato peels were ground into powders using a spice grinder (Waring spice grinder, model-WSG 30, Waring Products, Torrington, CT, USA). The powders were sieved through 45- and 100-mesh screens that allowed particles with a diameter smaller than 0.354 and $0.150 \mathrm{~mm}$, respectively, to pass through. Potato peel samples were then divided into four fractions according to their sizes: original (without grind), particles retained on the 45-mesh screen (referred to as $>45$ mesh), particles that passed through the 45 -mesh screen but retained on the 100-mesh screen (referred to 45-100 mesh), and particles that passed through the 100-mesh screen (referred to as $<100$ mesh). Potato peel powders were sealed in Ziploc ${ }^{\circledR}$ bags (S.C. Johnson \& Son, Inc., Racine, WI, USA) and stored at $-18^{\circ} \mathrm{C}$ until used.

All chemicals were reagent grade, obtained from Sigma-Aldrich Co. (St. Louis, MO, USA) or Fisher Scientific (Pittsburgh, PA, USA), and used without further purifications or treatments.

\subsection{Conventional Shaking Extraction (CSE)}

Potato peel powders $(0.25 \mathrm{~g})$ were extracted with $5 \mathrm{~mL}$ of methanol $(50 \%, v / v)$ in a glass cylinder, and then put in an incubator shaker (Environmental incubator shaker, G24, New Brunswick Co., Inc., Edison, NJ, USA) in triplicate. The incubator shaker was controlled at $25^{\circ} \mathrm{C}$ and $150 \mathrm{rpm}$, and the extraction time was $1,2,5,10,15,30,45$, and $60 \mathrm{~min}$. The mixture was centrifuged at $1500 \times \mathrm{g}$ for $15 \mathrm{~min}$ after extraction. Two samples were taken per extraction, and the total phenolic compounds (TPC) in the supernatant was quantified in triplicates. 


\subsection{Indirect Ultrasound-Assisted Extraction (IUAE)}

Ground peel powders $(0.25 \mathrm{~g})$ were suspended in $5 \mathrm{~mL}$ of methanol $(50 \%, v / v)$ and transferred into a glass cylinder, which was placed in an ultrasound water bath (SharperTek ${ }^{\circledR}$, Pontiac, MI, USA) set at a frequency of $40 \mathrm{kHz}(500 \mathrm{~W})$ at $25^{\circ} \mathrm{C}$ for $1,2,5,10,15,30,45$, and $60 \mathrm{~min}$. The mixture was centrifuged at $1500 \times g$ for $15 \mathrm{~min}$ after extraction, and the extraction under each condition was performed three times. The TPC in the supernatant was quantified in triplicates.

\subsection{Direct Ultrasound-Assisted Extraction (DUAE) and Temperature Measurement}

Potato peel powders were mixed with methanol and transferred to a glass cylinder, which was set in a water bath (Figure 1). An ultrasound probe was submerged $5 \mathrm{~mm}$ below the surface of the potato peel suspension in the glass cylinder. A thermocouple (E-Type Thermocouple Extension Wire, National Instruments, Roscoe, IL, USA) was inserted into the glass cylinder to monitor the temperature of potato peel suspension. The mixture temperature was automatically recorded by PicoLog recorder (PicoLog software version 5.25.3, Picolog Technology, TX, USA), and the peak temperature was reported. The setup of DUAE also consisted of a waveform generator (Agilent Technologies, model 33120A, Santa Clara, CA, USA), an amplifier (Amplifier Research, model 150A-100B, Pleasanton, CA, USA), an air-cooled piezoelectric converter (Sonics \& Materials. model CV-154, Newtown, CT, USA), and a probe (Sonotrode, model 1102, a diameter of $12.7 \mathrm{~mm}$, Sonics \& Materials, Newtown, CT, USA).

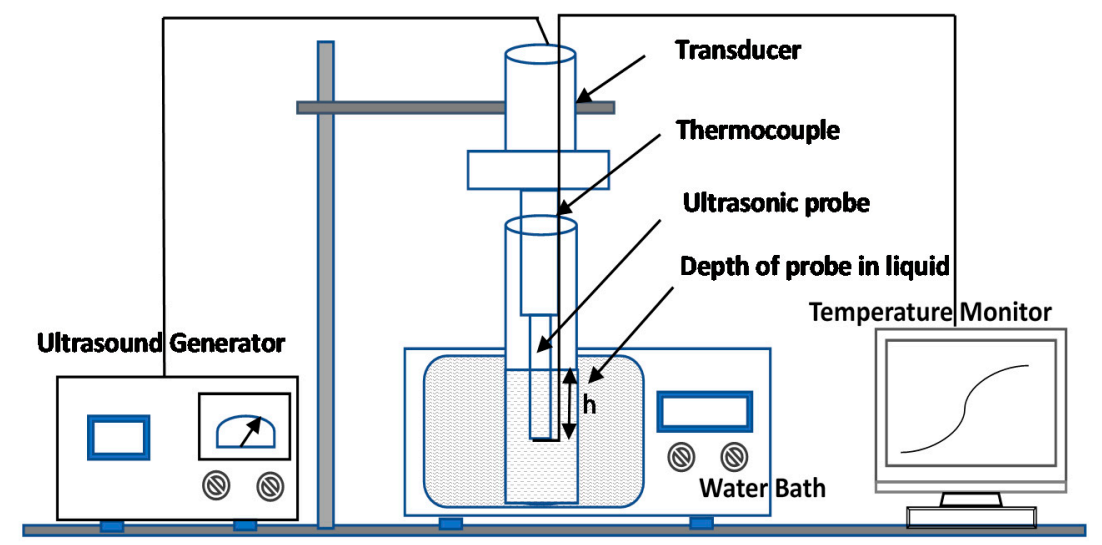

Figure 1. Schematic of the setup of direct ultrasound-assisted extraction (DUAE) method.

In order to understand the impact of ultrasound parameters on extraction efficiency, several parameters were examined in this study. The solvent-to-solid ratios were controlled at 10:1, 20:1, 40:1, and $60: 1$ by suspending $25 \mathrm{mg}$ (dry wt.) of potato peel powders with various amounts $(2.5,5,10$, or $15 \mathrm{~mL})$ of methanol $(50 \%, v / v)$. The temperature of the water bath was controlled at $-2,25,45$, and $60^{\circ} \mathrm{C}$. The ultrasonic probe was oscillated at a frequency of $22.95 \mathrm{kHz}$ with an output power of $120 \mathrm{~W}$ for 1, 2, 5, 10, 15, 30, 45, and $60 \mathrm{~min}$. The extractions were performed with various amplitudes, $200,400,600$, and 900 millivolts peak-to-peak (mVpp) of the input sine waveform. After the extraction, the mixture was centrifuged at $1500 \times g$ for $15 \mathrm{~min}$, and the TPC in each extract was quantified. Each extraction condition was performed in triplicates.

\subsection{Quantification of Total Phenolic Compounds (TPC) in Potato Peel Extracts}

Phenolic compounds in potato peel extracts were quantified using the Folin-Ciocalteu method of Mohdaly et al. [10] with modifications. The potato peel extract $(1 \mathrm{~mL})$ was mixed with $2 \mathrm{~mL}$ of 10-fold diluted Folin-Ciocalteu reagent in a tube, followed by adding $2 \mathrm{~mL}$ of sodium bicarbonate solution $(5 \%, w / v)$ to the mixture. The mixture was vortexed and then incubated at $25{ }^{\circ} \mathrm{C}$ for $30 \mathrm{~min}$. The absorbance of each mixture was measured at $765 \mathrm{~nm}$ using a UV-VIS spectrophotometer (Genesys-10S, Thermo Fisher Scientific, Waltham, MA, USA). Methanol $(50 \%, v / v)$ was used as the 
blank of the spectrophotometer measurement. Gallic acid solutions, $10-500 \mu \mathrm{g} / \mathrm{mL}$, were used to construct a calibration curve with absorbance against various concentrations. The yields of extraction were expressed as milligrams of gallic acid equivalents per gram dry weight of potato peel powders (mg GAE/g dry wt.).

\subsection{Examination of Potato Peel Powders with Scanning Electron Microscope (SEM)}

Potato peel powders, before and after extractions, were sputter-coated with a thin layer of gold-palladium for $60 \mathrm{~s}$ at $25^{\circ} \mathrm{C}$ and examined using a field-emission scanning electron microscope (Quanta 3D FEG, FEI Co., Hillsboro, OR, USA) at $10 \mathrm{kV}$.

\subsection{Determination of DPPH Radical Scavenging Activity of Extracted Phenolic Compounds}

The free radical scavenging activity of potato peel extracts on 2,2-diphenyl-1-picrylhydrazyl (DPPH) radicals was measured as described previously [5]. An aliquot $(50 \mu \mathrm{L})$ of potato peel extracts was added to DPPH $(1.5 \mathrm{~mL}, 3.94 \mathrm{mg} / 100 \mathrm{~mL}$ methanol). As free electrons in DPPH are paired off in the presence of antioxidants, the absorption decreases as the result of the extinction of the purple color of DPPH. Decolorization was determined by measuring the absorbance at $517 \mathrm{~nm}$ with a UV-VIS spectrophotometer after $20 \mathrm{~min}$ of reaction. The measurement was performed three times. The scavenging activity on DPPH radicals was calculated as percentage (\%) inhibition using the following equation [10]:

$$
\text { DPPH radical scavenging activity }(\%)=\left[\left(\mathrm{Abs}_{\text {control }}-\mathrm{Abs}_{\text {sample }}\right) / \mathrm{Abs}_{\text {control }}\right] \times 100
$$

\subsection{Statistical Analysis}

Analysis of variance was conducted using SPSS, Version 23.0 (SPSS Inc., Chicago, IL, USA). The Pearson correlation coefficient $(r)$ was calculated to demonstrate the linear correlations between variables. All results are presented as the mean $(M)$ of triplicate measurements. The level of significance was set at $p<0.05$.

\section{Results and Discussion}

\subsection{Comparison of Three Extraction Methods}

Figure 2 shows a significant difference of extraction efficiencies of the three methods by using TPC as a function of extraction times.

When comparing DUAE with CSE in Figure 2, the maximum yield of TPC from DUAE $(9.3 \mathrm{mg}$ GAE/g dry wt.) was about $48 \%$ higher than that of CSE (6.26 mg GAE/g dry wt.) with an extraction time of $60 \mathrm{~min}$. In addition, there was a significant difference in extraction rate between DUAE and CSE. Within $1 \mathrm{~min}$ of extraction, CSE generated $3.35 \mathrm{mg}$ GAE/g dry wt. of TPC, while DUAE generated $7.6 \mathrm{mg}$ GAE/g dry wt. of TPC, an amount that was about two times higher. In order to achieve this amount of TPC using the CSE, it would require more than $60 \mathrm{~min}$. The high efficiency of DUAE was associated with the phenomenon of ultrasound-induced cavitation. The collapse of cavitation bubbles produced ultrasonic jets. The ultrasonic jets further improved the infusion of the solvent to the solid particles, disrupted the potato peel cells, and enhanced the extraction of phenolic compounds from the potato peels $[20,21]$. The CSE was less efficient than DUAE. A prolonged extraction time could increase the TPC yield of CSE and decrease the difference in TPC yield between CSE and DUAE. The ultrasound probe in DUAE immersed in the potato peel suspension transferred higher ultrasonic energy to potato peels.

Data shown in Figure 2 also indicate that DUAE was more efficient than IUAE. The maximum yield of TPC using DUAE (9.33 mg GAE/g dry wt.) was about $2.6 \%$ higher than that of IUAE $(9.09 \mathrm{mg}$ GAE/g dry wt.) with an extraction time of $30 \mathrm{~min}$. To achieve a TPC yield of $7.6 \mathrm{mg} \mathrm{GAE} / \mathrm{g}$ dry wt., $1 \mathrm{~min}$ was needed for DUAE compared to $5 \mathrm{~min}$. of extraction time necessary when using IUAE. Thus, it can 
be noted that when extracting phenolic compounds from potato peels, the extraction efficiency of DUAE is about five times faster than IUAE. These experimental results agree with those of other researchers using similar methods for extracting phenolic compounds from various materials [22,23]. Compared to an ultrasound bath, the ultrasound probe delivers a higher power to promote mass transfer. Capelo-Martinez et al. [24] explain that the ultrasound probe, which is immersed directly in the extraction mixture, transferred higher ultrasonic energy to the samples, as the ultrasonic waves do not need to cross both the water in the bath and the cylinder wall before reaching the sample to be treated. However, there was little significant difference in TPC yield between these two ultrasound treatment methods after a prolonged extraction time (30 min.), which differs from the results attained from our previous work with walnut shells [25].

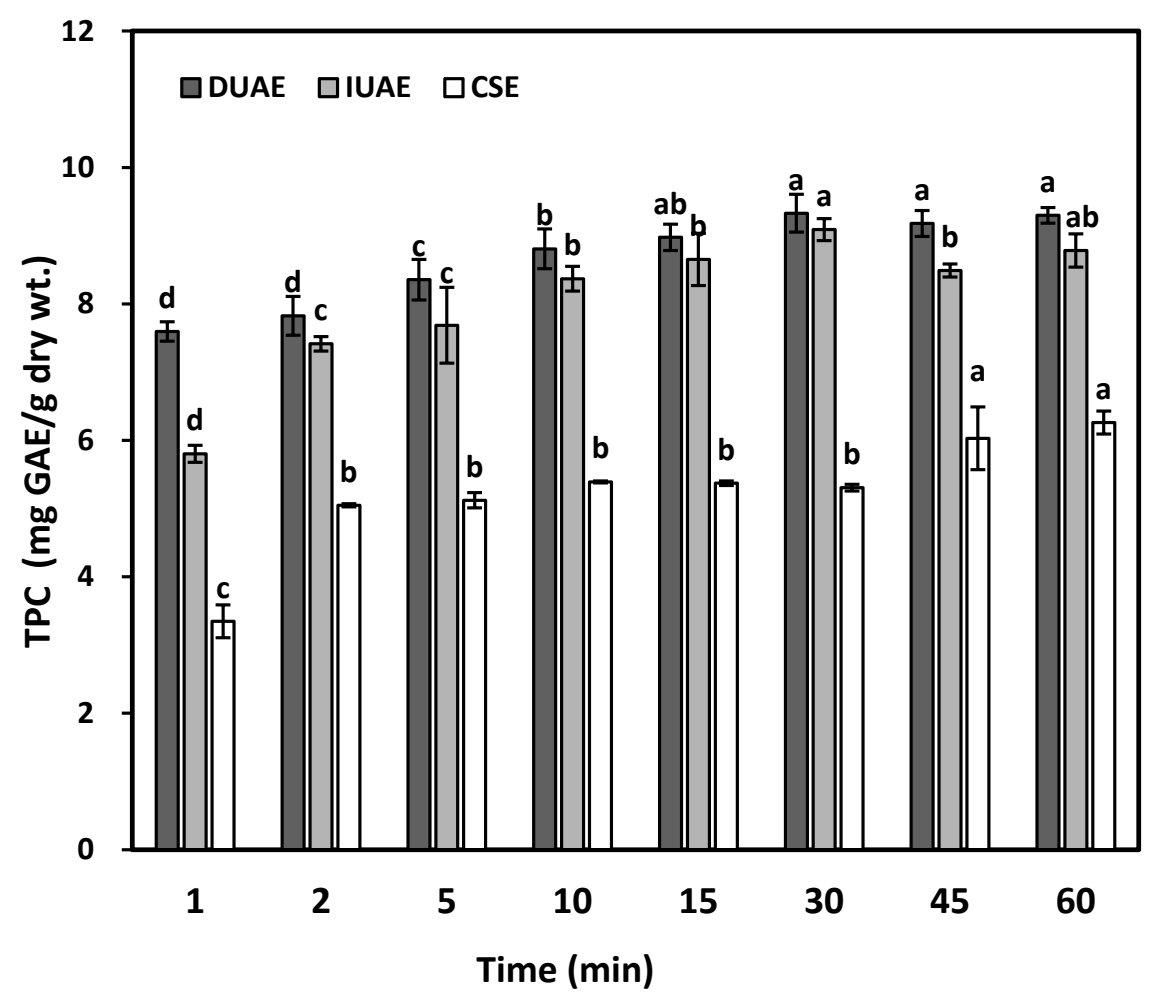

Figure 2. Yields of total phenolic compounds (TPC) from potato peels extracts obtained using the conventional shaking extraction (CSE), direct ultrasound-assisted extraction (DUAE), and indirect ultrasound-assisted extraction (IUAE) methods. Data are means of three measurements, and the error bars indicate standard deviations. Data denoted with the same letter (a, b, c, or d) were not significantly different from the same extraction method at different timings $(p>0.05)$. Setting for the two ultrasound methods, DUAE and IUAE, were $23 \mathrm{kHz}, 25{ }^{\circ} \mathrm{C}$ water bath temperature, $600 \mathrm{mVpp}$, solvent-to-solid ratio 40:1, and particle size smaller than $0.354 \mathrm{~mm}$.

The morphology of potato peel cells was examined by SEM. The untreated potato peels had closed cells with rough surfaces (Figure 3a). All three methods caused a significant expansion in cell volume. In the CSE method, the surface of potato peel cells became smooth with cracks in some cells (Figure 3b). Both ultrasound-assisted methods produced some ruptured cells with large perforations (Figure 3c,d), and these phenomena were caused by cavitation. DUAE caused more damage to cells with hollow openings (Figure 3d) than IUAE and CES. The disrupting of potato peel cells allowed the solvent to penetrate into cells and accelerated the release of phenolic compounds from potato peels. 


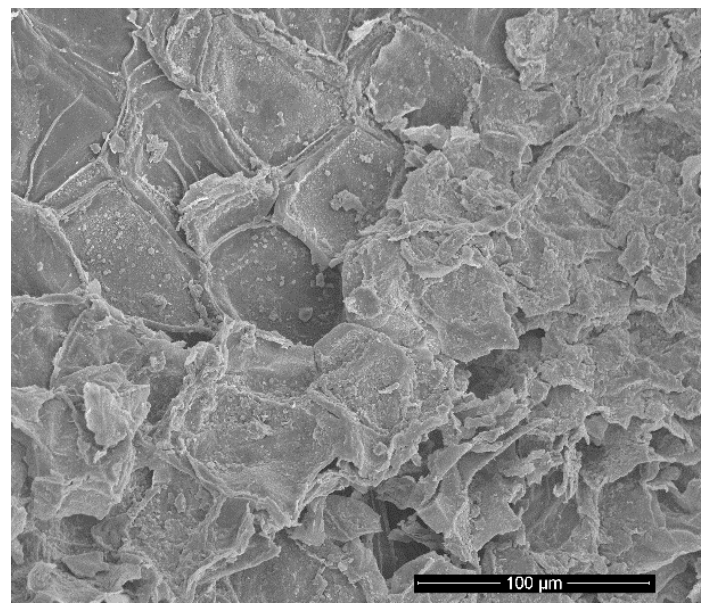

(a)

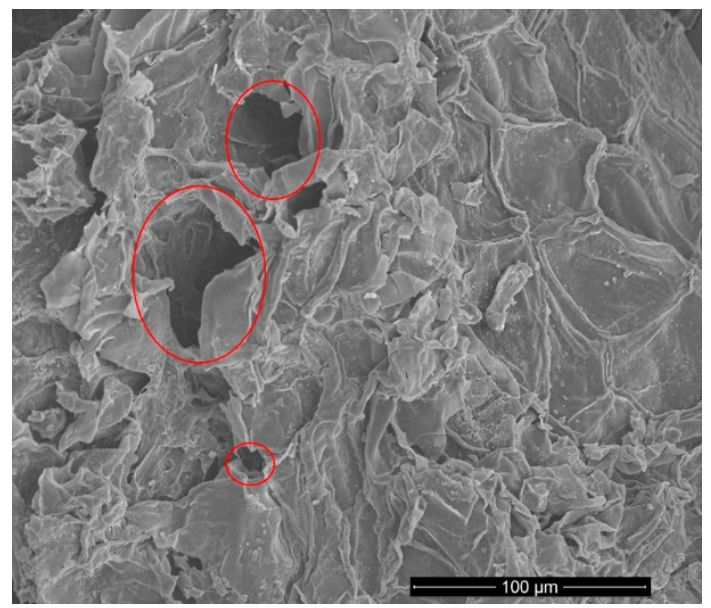

(c)

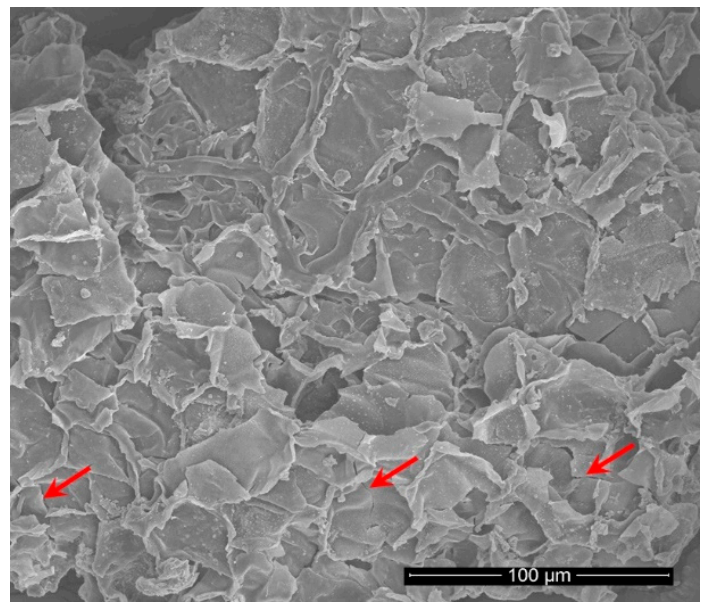

(b)

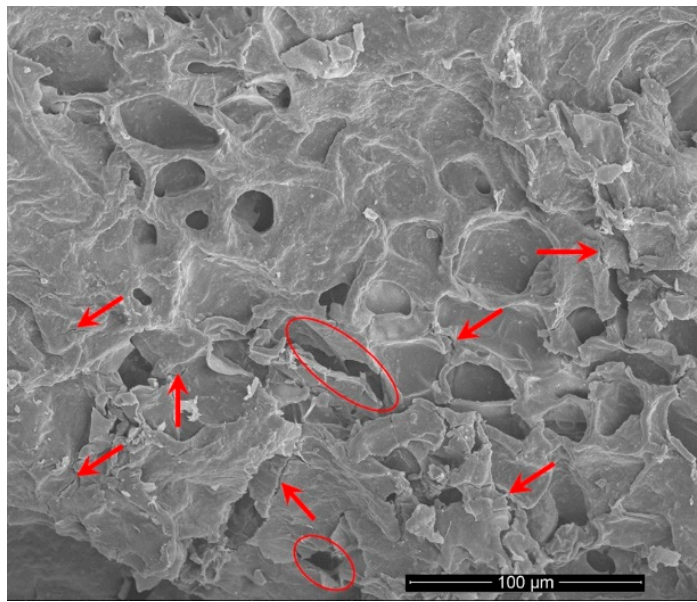

(d)

Figure 3. SEM images of cells in potato peels before extraction (a), after extraction by the CSE method (b), after extraction by the IUAE method (c), and after extraction by the DUAE method (d). All three methods were conducted with a solvent-to-solid ratio of $40: 1$ in a water bath controlled at $25{ }^{\circ} \mathrm{C}$ for $30 \mathrm{~min}$.

\subsection{Parameters Affecting the Yield of TPC Using the DUAE Method}

\subsubsection{Effects of Extraction Time on TPC Yield}

Prolonged extraction time produced a higher yield of TPC. The yield was $7.60 \mathrm{mg}$ GAE/g dry wt. at $1 \mathrm{~min}$ and $9.30 \mathrm{mg} \mathrm{GAE} / \mathrm{g}$ dry wt. at $60 \mathrm{~min}$ of extraction (Figure 4). Because the extraction of phenolic compounds is a diffusion-controlled process, the yield was time dependent. These results also agree with those of researchers who attribute the effect of ultrasound on the extraction yield to acoustic-induced effects, such as cavitation, streaming, and shock waves [26,27]. During the extraction, both the TPC yield and temperature of the potato peel suspensions were at or near the peak values after $45 \mathrm{~min}$ in a constant water bath temperature of $25^{\circ} \mathrm{C}$. Increasing the extraction time to $60 \mathrm{~min}$ did not further increase TPC yield, and the mixture temperature decreased from $50.5^{\circ} \mathrm{C}$ to $48{ }^{\circ} \mathrm{C}$. Results showed that TPC yield correlated more with mixture temperature $(r=0.974, p<0.01)$ than with extraction time $(r=0.795, p=0.11)$. Findings in this study suggest a need to balance the temperature and reaction time during extraction. 


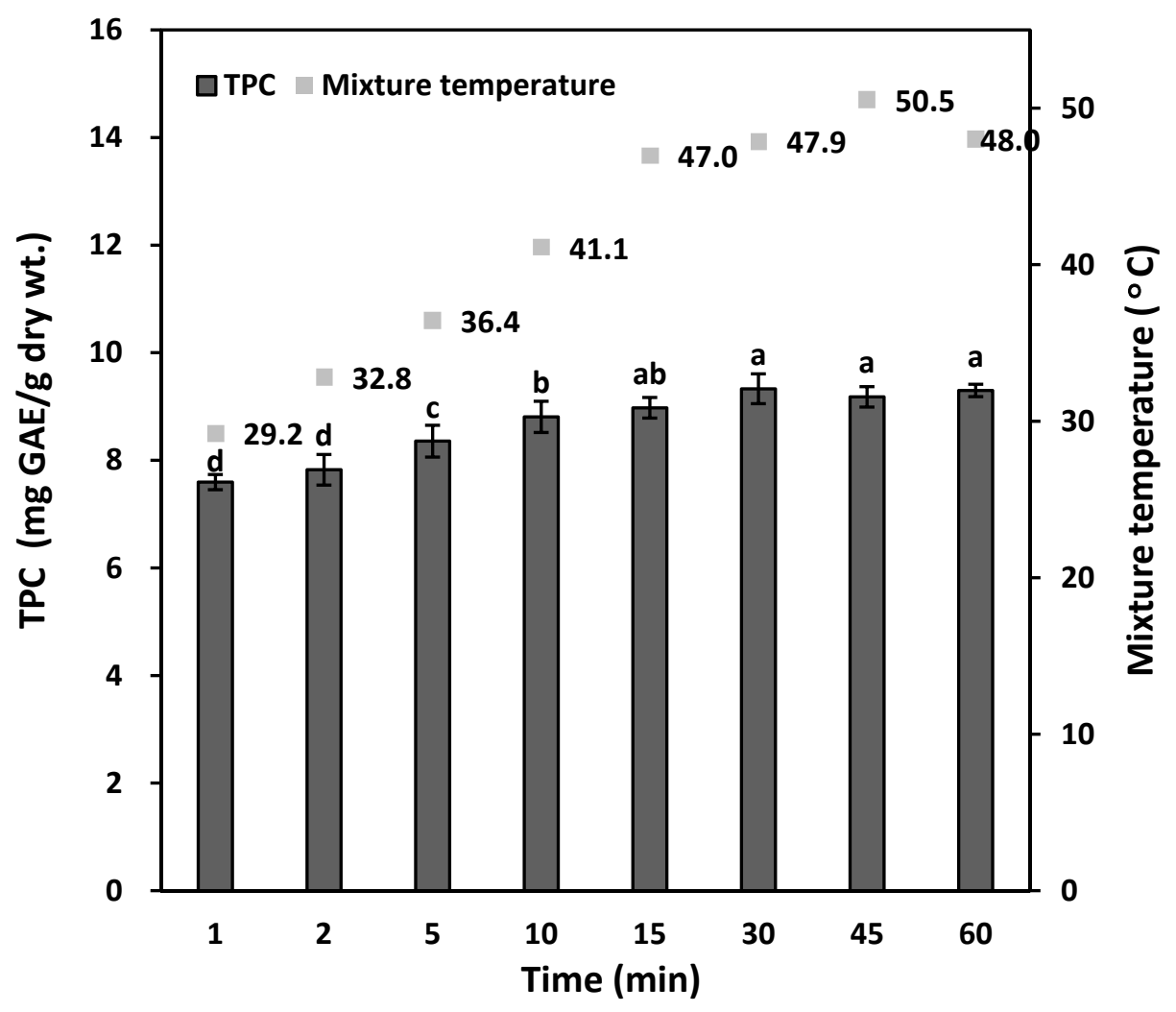

Figure 4. The relationship among the yield of total phenolic compounds (TPC), extraction time (min), and the temperature of potato peels suspension in DUAE. Numbers indicated in the graph denote the temperature of the potato peels suspension. Data are means of three measurements, and error bars indicate standard deviations. Data denoted with the same letter $(a, b, c$, or d) were not significantly different $(p>0.05)$. Ultrasound extraction parameters were $23 \mathrm{kHz}, 600 \mathrm{mVpp}$, water bath temperature $25^{\circ} \mathrm{C}$, solvent-to-solid ratio 40:1, and particle size smaller than $0.354 \mathrm{~mm}$.

The ultrasonic energy injected into the glass container heated up the mixture directly, and the heat exchange between the glass container and the water bath was not enough to overcome the temperature increase in the container. As a result, in our experiments, the temperature in the mixture was higher than the bath temperature during the DUAE of phenolic compounds from potato peels. Further research is required to confirm if the mixture temperature affects the solubility of phenolic compounds in the solvent.

\subsubsection{Effects of Extraction Temperature on TPC Yield}

Temperature greatly affects extraction efficiency. However, the actual reaction temperature of potato peels suspension almost always deviated from the water bath temperature. The ultrasonic energy injected into the glass cylinder, where it holds the potato peel suspension, heat up the mixture quickly. However, the heat transfer between the glass cylinder and water bath was not quick enough to offset the temperature difference. In this study, the water bath temperature was controlled at $-2,25,45$, and $60^{\circ} \mathrm{C}$, but the mixture temperature was found to be $13.8,47.9,53.0$, and $69.5^{\circ} \mathrm{C}$, respectively (Figure 5). Results showed that both water bath temperature and mixture temperature positively correlated with TPC yield. It has been shown that high temperature reduces the surface extension of solvents [25], increases solvent solubility, enhances the infusion of solvent into potato cells, and promotes the disruption of cells [28]. Results of this study showed that both mixture temperature $(r=0.993, p=0.02)$ and water bath temperature $(r=0.967, p=0.08)$ were correlated with TPC yields. 


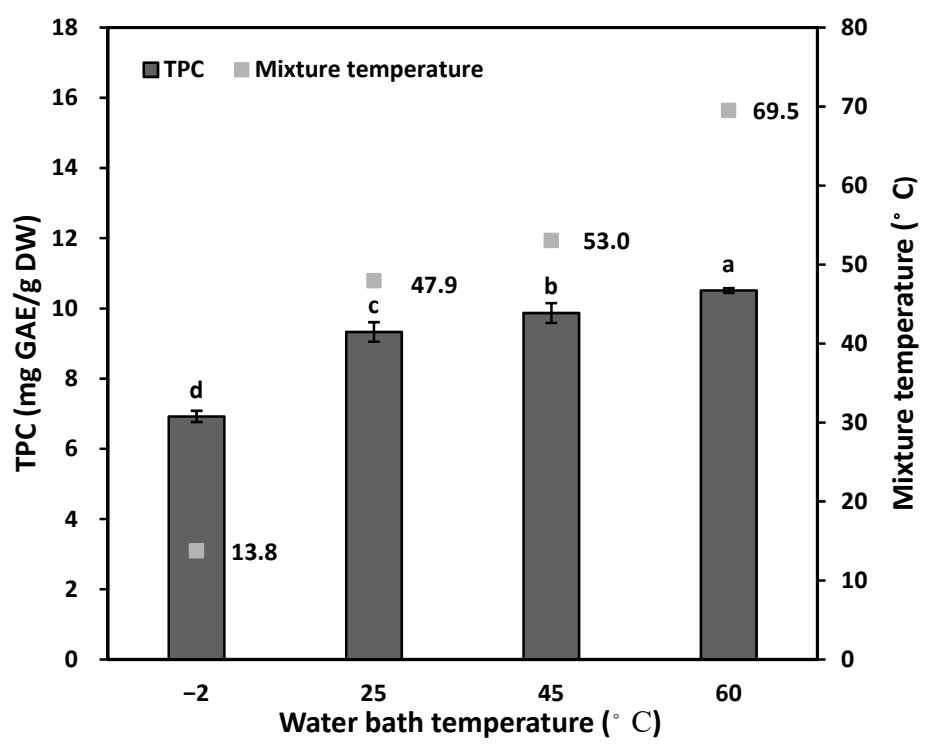

Figure 5. The relationship among the yield of total phenolic compounds (TPC), water bath temperature, and mixture temperature in DUAE. Numbers indicated in the graph denote the mixture temperature. Data are means of three measurements, and error bars are standard deviations. Data denoted with the same letter $(\mathrm{a}, \mathrm{b}, \mathrm{c}$, or $\mathrm{d})$ were not significantly different $(p>0.05)$. The ultrasound extraction parameters were $23 \mathrm{kHz}, 600 \mathrm{mVpp}$, solvent-to-solid ratio 40:1, 30-min extraction, and particle size smaller than $0.354 \mathrm{~mm}$.

\subsubsection{Effects of Amplitude of Ultrasonic Vibration on TPC Yield}

The amplitude of the input sine waveform also had a positive impact on the extraction yield. When the amplitude was increased from $200 \mathrm{mVpp}$ to $400 \mathrm{mVpp}$ and $600 \mathrm{mVpp}$, the TPC yield increased from $7.67 \mathrm{GAE} / \mathrm{g}$ to $9.12 \mathrm{GAE} / \mathrm{g}$ and $9.33 \mathrm{GAE} / \mathrm{g}$ dry wt., respectively (see Figure 6). While the amplitude was $200,400,600$, and $900 \mathrm{mVpp}$, the mixture temperature was $32.1,41.8,47.9$, and $50.2^{\circ} \mathrm{C}$, respectively, despite the water bath temperature being at $25^{\circ} \mathrm{C}$. It has been shown that high ultrasound amplitude delivers more power to the mixture of potato peels suspension, increases mixture temperature, enhances solvent penetration, and induces more cavitation damage to cell walls $[27,28]$. Results showed that TPC yield strongly correlated with both temperature $(r=0.962, p<0.01)$ and ultrasound amplitude $(r=0.800, p=0.05)$.

There was no significant improvement in TPC yield when the amplitude was increased from 600 to $900 \mathrm{mVpp}$. Capelo-Martinez [24] reported that high amplitude could degrade extracts. When the amplitude reached a level at which extraction and degradation offset each other, no further increase in yield would be observed. Rakita and Han [29] reported that stable cavitation could be obtained between 200 and $300 \mathrm{mVpp}$ in pure water. Results from this study indicated that the balance was at $600 \mathrm{mVpp}$. The higher amplitude shortened the time to achieve the maximum TPC yield, but did not further increase the yield.

\subsubsection{Effects of Solvent-to-Solid Ratio on TPC Yield}

The extraction yields were 7.16, 9.44, 9.33, and $10.02 \mathrm{mg} \mathrm{GAE} / \mathrm{g}$ dry wt. when the solvent-to-solid ratios were 10:1, 20:1, 40:1, and 60:1, respectively (Figure 7). Increasing the ratio of solvent-to-solid from 10:1 to 20:1 improved the yield, but a further increase in the ratio had no additional effect. The mass transfer from solid to solvent is concentration-dependent. Therefore, an increase in the solvent resulted in a better defection rate. An increase in the solvent-to-solid ratio was found to enlarge the difference between the temperature of the water bath and the mixture of potato peels suspension. It has been observed that a large amount of cavitation bubbles was formed when a high solvent-to-solid ratio was applied to the extraction. Results showed that TPC yield had a strong relationship with both mixture temperature $(r=0.816, p=0.01)$ and solvent-to-solid ratio $(r=0.796, p=0.11)$. 


\subsubsection{Effects of the Particle Size of Potato Peels on TPC Yield}

Results in this study showed that the extraction yields were 2.54, 7.48, 9.26, and $10.29 \mathrm{mg} \mathrm{GAE} / \mathrm{g}$ dry weight when the particle sizes of potato peel powders were original $(20-30 \mathrm{~mm}),>45 \mathrm{mesh}$ ( $>0.354 \mathrm{~mm}), 45-100$ mesh $(0.354-0.150 \mathrm{~mm})$, and $<100$ mesh $(0.150 \mathrm{~mm})$, respectively (Figure 8$)$. Finer particles were found to generate much higher yield, as small particles have a bigger total surface area and shorter solvent diffusion path. The mixture temperature of finer particles was higher than that of bigger particles. The mixture temperature of particles $2-3 \mathrm{~mm}$ and smaller than $0.15 \mathrm{~mm}$ were $39.1{ }^{\circ} \mathrm{C}$ and $52.4^{\circ} \mathrm{C}$, respectively. It was claimed that the ultrasound energy is absorbed more in the mixture having a greater area of particle/liquid interface. Such solid-liquid interface with the ultrasound-induced shear flow dissipates ultrasonic energy into heat in the solvent, resulting in an increased temperature in the mixture.

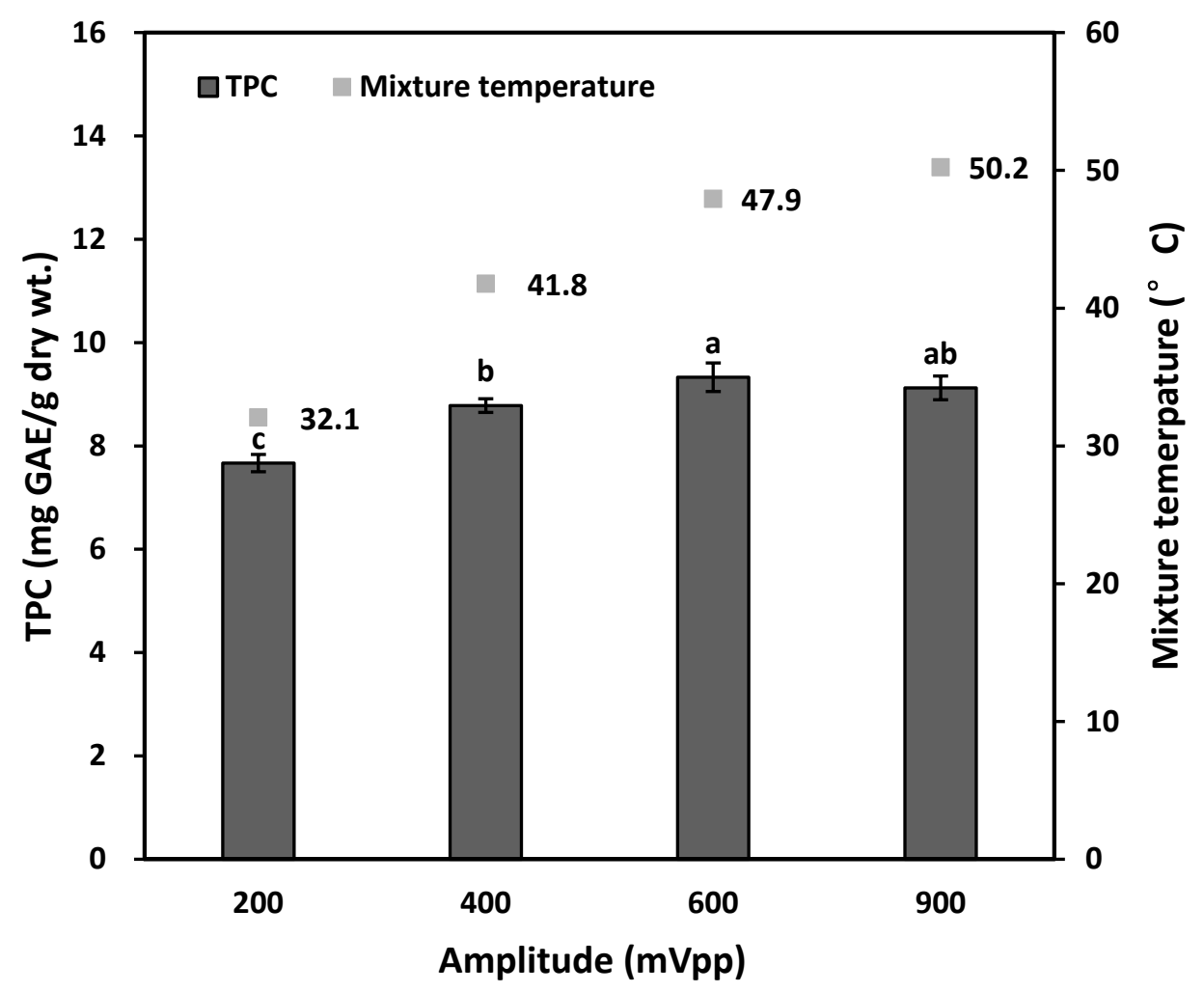

Figure 6. Relationships among the yield of total phenolic compounds (TPC), extraction amplitude, and mixture temperature in DUAE. Numbers indicated in the graph denote the temperature of the potato peels suspension. Data are means of three measurements, and error bars indicate standard deviations. Data denoted with the same letter $(\mathrm{a}, \mathrm{b}, \mathrm{c}$, or $\mathrm{d})$ were not significantly different $(p>0.05)$. Ultrasound extraction parameters were $23 \mathrm{kHz}, 600 \mathrm{mVpp}$, water bath temperature $25^{\circ} \mathrm{C}$, solvent-to-solid ratio 40:1, and particle size smaller than $0.354 \mathrm{~mm}$. 


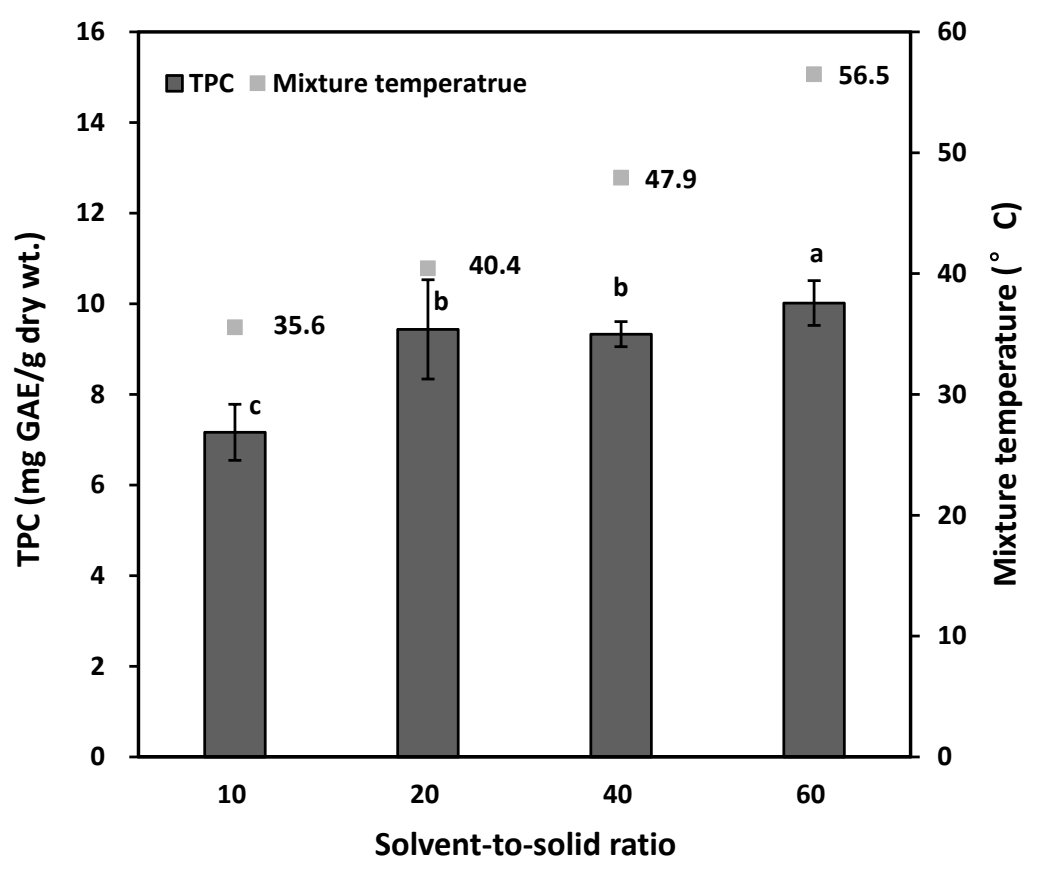

Figure 7. The relationship among the yield of total phenolic compounds (TPC), solvent-to-solid ratio, and mixture temperature in DUAE. Numbers indicated in the graph denote the temperature of the potato peels suspension. Data are means of three measurements, and error bars indicate standard deviations. Data denoted with the same letter ( $a, b, c$, or d) were not significantly different $(p>0.05)$. Ultrasound extraction parameters were $23 \mathrm{kHz}, 600 \mathrm{mVpp}$, water bath temperature $25^{\circ} \mathrm{C}$, solvent-to-solid ratio 40:1, and particle size smaller than $0.354 \mathrm{~mm}$.

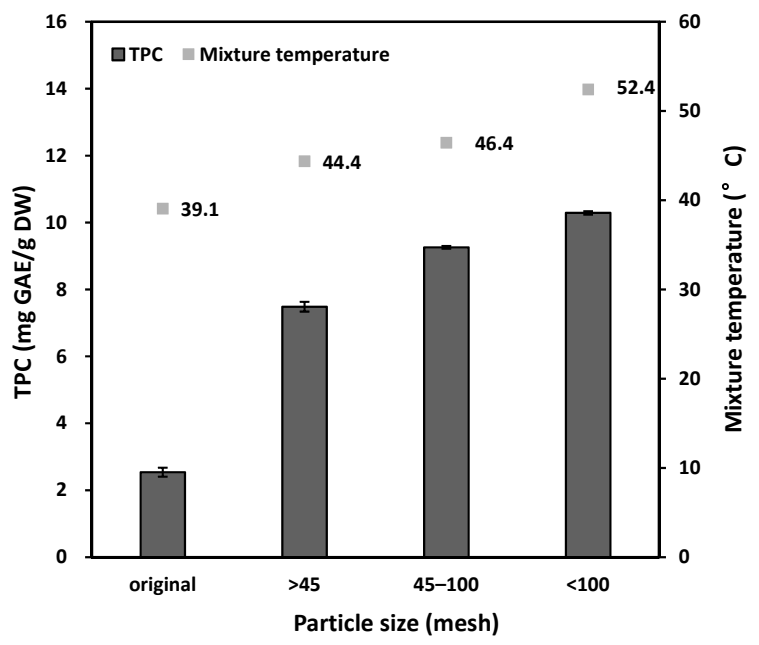

Figure 8. The relationship among the yield of total phenolic compounds (TPC), particle size, and mixture temperature during the DUAE extraction. Numbers indicated in the graph denote the temperature of the potato peels suspension. Data are means of three measurements, and error bars indicate standard deviations. Data denoted with the same letter $(\mathrm{a}, \mathrm{b}, \mathrm{c}, \mathrm{or} \mathrm{d})$ were not significantly different $(p>0.05)$. Ultrasound extraction parameters were $23 \mathrm{kHz}, 600 \mathrm{mVpp}$, water bath temperature $25^{\circ} \mathrm{C}$, and solvent-to-solid ratio 40:1. Particle sizes: $20-30 \mathrm{~mm}$ (original); $>45$ mesh (>0.354 mm); 45-100 mesh $(0.354-0.150 \mathrm{~mm})$; and $<100$ mesh $(<0.150 \mathrm{~mm})$.

\subsection{Scavenging Activity of Phenolic Compounds Extracted from Potato Peels}

Plant phenolic compounds are natural antioxidants for delaying the oxidation of oils and fats in food during storage. With the concern of their negative impact on health, synthetic antioxidants, such as tert-butylhydroquinone (TBHQ), butylated hydroxytoluene (BHT), and butylated hydroxyanisole 
(BHA), are less desired [27]. To confirm the antioxidant activity of potato peel extracts generated by the DUAE method, their free radical scavenging activity on 2,2-diphenyl-1-picrylhydrazyl (DPPH) was determined. Results showed that the antioxidant activities of the potato peel extract correlated with the quantity of TPC in the potato peel extracts $(p<0.05$; Figure 9). Our findings suggest that the antioxidant activity in potato peel extracts was primarily influenced by the quantity of phenolic compounds, results that agree with the findings of other researchers [30]. As detailed by many reports, the phenolic compounds in potato peels contain higher amounts of phenolic acids and flavonoids $[1,2]$. These components have great antioxidant activity. Therefore, potato peels have the potential to be used as a natural source of antioxidants in the food and agriculture industry [31].

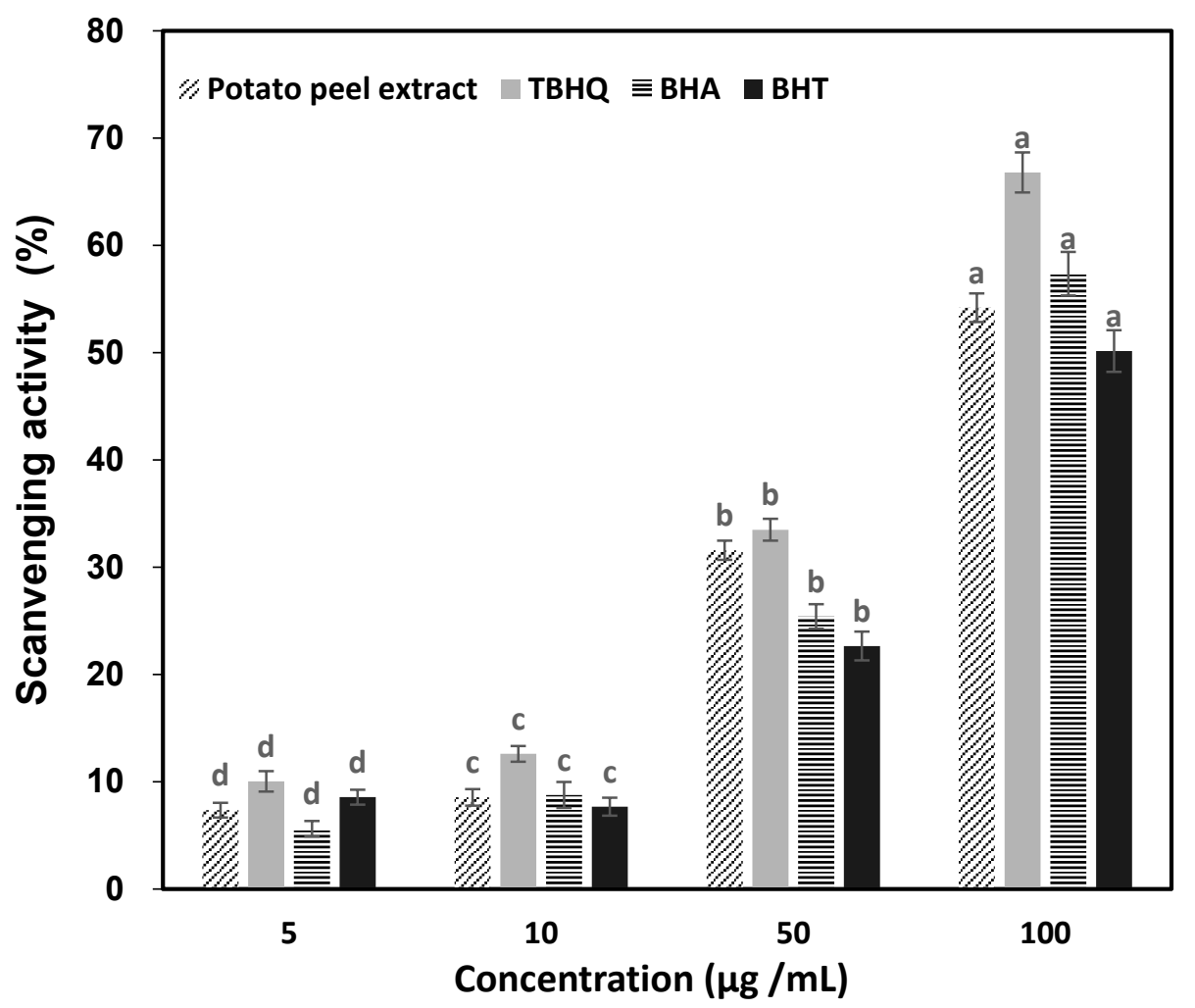

Figure 9. Scavenging activity of potato peel extract compared with that of tert-butylhydroquinone (TBHQ), butylated hydroxyanisole (BHA), and butylated hydroxytoluene (BHT). Data are means of three measurements, and error bars indicate standard deviations. Data denoted with the same letter $(\mathrm{a}, \mathrm{b}, \mathrm{c}$, or $\mathrm{d}$ ) were not significantly different $(p>0.05)$. DUAE parameters were $23 \mathrm{kHz}, 600 \mathrm{mVpp}$, water bath temperature $25^{\circ} \mathrm{C}$, solvent-to-solid ratio 40:1, 30-min extraction, and particle size smaller than $0.354 \mathrm{~mm}$.

The antioxidant activity of potato peel extracts was further compared with TBHQ, BHA, and BHT. The comparison was normalized to the quantity of total phenolic compounds (Section 2.5). At the concentration of $50 \mu \mathrm{g} / \mathrm{mL}$, the scavenging activities of the potato peel extracts and TBHQ were higher than that of BHA and BHT. At a higher concentration of $100 \mu \mathrm{g} / \mathrm{mL}$, TBHQ had the highest antioxidant activity $(66.8 \%)$, followed by BHA $(57.4 \%)$ and the potato peel extracts $(54.2 \%)$, while BHT had the lowest antioxidant activity (50.2\%). These results suggest that DUAE-extracted potato peels extract is comparable to that of these synthetic antioxidant products.

\section{Conclusions}

This study demonstrates the effectiveness of the DUAE of valuable antioxidants from potato peels. The direct contact of an ultrasound probe with potato peel suspension greatly enhanced the extraction efficiency. The extraction yield of TPC using DUAE was about two times higher than that 
of CBS at one minute, and the maximum yield of TPC was $48 \%$ higher than that of CSE. To achieve a TPC of $7.6 \mathrm{mg} \mathrm{GAE} / \mathrm{g}$ dry wt., it took $1 \mathrm{~min}$ using DUAE, 5 min using IUAE, and more than 60 min using CSE. The setup of DUAE in this study allowed the reaction temperature to be measured, and it was discovered that a balance of reaction time and temperature was needed for obtaining the maximum yield of total phenolic compounds. The high efficiency of DUAE was associated with the transfer of high ultrasound energy and temperature to potato peel suspension. DUAE generated more disruption of potato cells, but did not diminish the antioxidant activity. DUAE-extracted potato peel extract had comparable antioxidant activity to popular synthetic antioxidants. Findings of this study suggest that DUAE has the potential to transform a large number of potato peels to valuable ingredients, and, thus, promote sustainability. Further research for pre-treatment of potato peels, such as cleaning, and removal of undesired compounds, such as alkaloids, is recommended. Moreover, to further investigate the mechanism of the antioxidant activity of phenolic extracts from potato peels, additional purification steps and determination of phenolic profiles by HPLC are required. In summary, this preliminary study proved the concept of using a simplified ultrasound extraction to increase profitability for the potato industry by producing antioxidants from potato peels.

Author Contributions: Investigation: Q.X. and S.W.; resources: Q.X., Q.H., and A.H.-M.L.; writing-original draft preparation: S.W.; writing-review and editing: Q.X., Q.H., and A.H.-M.L.; supervision: Q.X. and A.H.-M.L. All authors have read and agreed to the published version of the manuscript.

Funding: This research was funded by John \& Emma Tse, Li-Fu Chen Memorial Laboratory Fund and the Center for Materials Processing Research at Purdue University (W. Lafayette, IN, USA); Science and Technology Department of Jilin Province (No. 20170101108JC, Jilin, China); Idaho State Department of Agriculture Specialty Crop Block Grant Program-Farm Bill 2015 (15-SCBGP-ID-0015); and the Potato Research Endowment (FY 2014) sponsored by Basic American Foods (Blackfoot, ID, USA) at University of Idaho (Moscow, ID, USA).

Acknowledgments: We thank Xingtao Liu for assistance with SEM examinations, and Wilson $\mathrm{Xu}$ and Milan Rakita (Purdue University, W. Lafayette, IN, USA) for operating the ultrasound equipment and participating in the discussion. We appreciate Basic American Foods for providing potato peels. We acknowledge Laurie L Van Keppel (Purdue University, W. Lafayette, IN, USA) and Hannah Han (University of California, Los Angeles, USA) for editing the manuscript.

Conflicts of Interest: The authors declare no conflict of interest.

\section{References}

1. Singh, B.; Singh, J.; Singh, J.P.; Kaur, A.; Singh, N. Phenolic compounds in potato (Solanum tuberosum L.) peel and their health-promoting activities. Int. J. Food Sci. Technol. 2020, 55, 2273-2281. [CrossRef]

2. Akyol, H.; Riciputi, Y.; Capanoglu, E.; Caboni, M.F.; Verardo, V. Phenolic Compounds in the Potato and Its Byproducts: An Overview. Int. J. Mol. Sci. 2016, 17, 835. [CrossRef] [PubMed]

3. Kumari, B.; Tiwari, B.K.; Hossain, M.B.; Rai, D.K.; Brunton, N.P. Ultrasound-assisted extraction of polyphenols from potato peels: Profiling and kinetic modelling. Int. J. Food Sci. Technol. 2017, 52, 1432-1439. [CrossRef]

4. Al-Weshahy, A.; Rao, A.V. Isolation and characterization of functional components from peel samples of six potatoes varieties growing in Ontario. Food Res. Int. 2009, 42, 1062-1066. [CrossRef]

5. Singh, A.; Sabally, K.; Kubow, S.; Donnelly, D.J.; Gariepy, Y.; Orsat, V.; Raghavan, G.S. Microwave-assisted extraction of phenolic antioxidants from potato peels. Molecules 2011, 16, 2218-22132. [CrossRef] [PubMed]

6. Albishi, T.; John, J.A.; Al-Khalifa, A.S.; Shahidi, F. Phenolic content and antioxidant activities of selected potato varieties and their processing by-products. J. Funct. Foods 2013, 5, 590-600. [CrossRef]

7. Arun, K.B.; Chandran, J.; Dhanya, R.; Krishna, P.; Jayamurthy, P.; Nisha, P. A comparative evaluation of antioxidant and antidiabetic potential of peel from young and matured potato. Food Biosci. 2015, 9, 36-46. [CrossRef]

8. Pereira, D.M.; Valentão, P.; Pereira, J.A.; Andrade, P.B. Phenolics: From chemistry to biology. Molecules 2009, 14, 2202-2211. [CrossRef]

9. Balasundram, N.; Sundram, K.; Samman, S. Phenolic compounds in plants and agri-industrial by-products: Antioxidant activity, occurrence, and potential uses. Food Chem. 2006, 99, 191-203. [CrossRef]

10. Mohdaly, A.A.A.; Sarhan, M.A.; Smetanska, I.; Mahmoud, A. Antioxidant properties of various solvent extracts of potato peel, sugar beet pulp and sesame cake. J. Sci. Food Agric. 2010, 90, 218-226. [CrossRef] 
11. van Esch, G.J. Toxicology of tert-butylhydroquinone (TBHQ). Food Chem. Toxicol. 1986, 24, $1063-1065$. [CrossRef]

12. Borah, P.P.; Das, P.; Badwaik, L.S. Ultrasound treated potato peel and sweet lime pomace based biopolymer film development. Ultrason. Sonochem. 2017, 36, 11-19. [CrossRef] [PubMed]

13. Sánchez Maldonado, A.F.; Mudge, E.; Gänzle, M.G.; Schieber, A. Extraction and fractionation of phenolic acids and glycoalkaloids from potato peels using acidified water/ethanol-based solvents. Food Res. Int. 2014, 65, 27-34. [CrossRef]

14. Wu, Z.G.; Xu, H.Y.; Ma, Q.; Cao, Y.; Ma, J.N.; Ma, C.M. Isolation, identification and quantification of unsaturated fatty acids, amides, phenolic compounds and glycoalkaloids from potato peel. Food Chem. 2012, 135, 2425-2429. [CrossRef] [PubMed]

15. Jacotet-Navarro, M.; Rombaut, N.; Fabiano-Tixier, A.S.; Danguien, M.; Bily, A.; Chemat, F. Ultrasound versus microwave as green processes for extraction of rosmarinic, carnosic and ursolic acids from rosemary. Ultrason. Sonochem. 2015, 27, 102-109. [CrossRef] [PubMed]

16. Galhano dos Santos, R.; Ventura, P.; Bordado, J.C.; Mateus, M.M. Valorizing potato peel waste: An overview of the latest publications. Rev. Environ. Sci. Bio/Technol. 2016, 15, 585-592. [CrossRef]

17. Kumari, B.; Tiwari, B.K.; Hossain, M.B.; Brunton, N.P.; Rai, D.K. Recent advances on application of ultrasound and pulsed electric field technologies in the extraction of bioactives from agro-industrial by-products. Food Bioprocess Technol. 2018, 11, 223-241. [CrossRef]

18. Garcia-Salas, P.; Morales-Soto, A.; Segura-Carretero, A.; Fernandez-Gutierrez, A. Phenolic-compoundextraction systems for fruit and vegetable samples. Molecules 2010, 15, 8813-8826. [CrossRef]

19. Patist, A.; Bates, D. Ultrasonic innovations in the food industry: From the laboratory to commercial production. Innov. Food Sci. Emerg. Technol. 2008, 9, 147-154. [CrossRef]

20. Friedman, M.; Kozukue, N.; Kim, H.J.; Choi, S.H.; Mizuno, M. Glycoalkaloid, phenolic, and flavonoid content and antioxidative activities of conventional nonorganic and organic potato peel powders from commercial gold, red, and Russet potatoes. J. Food Compos. Anal. 2017, 62, 69-75. [CrossRef]

21. Esclapez, M.D.; García-Pérez, J.V.; Mulet, A.; Cárcel, J.A. Ultrasound-Assisted Extraction of Natural Products. Food Eng. Rev. 2011, 3, 108-120. [CrossRef]

22. Hossain, M.B.; Brunton, N.P.; Patras, A.; Tiwari, B.; O’Donnell, C.P.; Martin-Diana, A.B.; Barry-Ryan, C. Optimization of ultrasound assisted extraction of antioxidant compounds from marjoram (Origanum majorana L.) using response surface methodology. Ultrason. Sonochem. 2012, 19, 582-590. [CrossRef] [PubMed]

23. Ghafoor, K.; Choi, Y.H.; Jeon, J.Y.; Jo, I.H. Optimization of ultrasound-assisted extraction of phenolic compounds, antioxidants, and anthocyanins from grape (Vitis vinifera) seeds. J. Agric. Food Chem. 2009, 57, 4988-4994. [CrossRef] [PubMed]

24. Capelo-Martínez, J.-L. Ultrasound in Chemistry: Analytical and Applications; Wiley-VCH: Weinheim, Germany, 2009; pp. 55-76.

25. Han, H.; Wang, S.; Rakita, M.; Wang, Y.; Han, Q.; Xu, Q. Effect of ultrasound-assisted extraction of phenolic compounds on the characteristics of walnut shells. Food Nutr. Sci. 2018, 9, 1034-1045. [CrossRef]

26. Riciputi, Y.; Diaz-de-Cerio, E.; Akyol, H.; Capanoglu, E.; Cerretani, L.; Caboni, M.F.; Verardo, V. Establishment of ultrasound-assisted extraction of phenolic compounds from industrial potato by-products using response surface methodology. Food Chem. 2018, 269, 258-263. [CrossRef]

27. Samarin, A.M.; Poorazarang, H.; Hematyar, N.; Elhamirad, A. Phenolics in potato peels: Extraction and utilization as natural antioxidants. World Appl. Sci. 2012, 18, 191-195.

28. Chemat, F.; Rombaut, N.; Sicaire, A.-G.; Meullemiestre, A.; Fabiano-Tixier, A.-S.; Abert-Vian, M. Ultrasound assisted extraction of food and natural products: Mechanisms, techniques, combinations, protocols and applications. A review. Ultrason. Sonochem. 2017, 34, 540-560. [CrossRef]

29. Rakita, M.; Han, Q. Influence of pressure field in melts on the primary nucleation in solidification processing. Metall. Mater. Trans. B 2017, 48, 2232-2244. [CrossRef]

30. Singh, N.; Kamath, V.; Narasimhamurthy, K.; Rajini, P.S. Protective effect of potato peel extract against carbon tetrachloride-induced liver injury in rats. Environ. Toxicol. Pharmacol. 2008, 26, 241-246. [CrossRef]

31. Javed, A.; Ahmad, A.; Tahir, A.; Shabbir, U.; Nouman, M.; Hameed, A. Potato peel waste-Its nutraceutical, industrial and biotechnological applications. AIMS Agric. and Food 2019, 4, 807-823. 
Publisher's Note: MDPI stays neutral with regard to jurisdictional claims in published maps and institutional affiliations.

(c)

(C) 2020 by the authors. Licensee MDPI, Basel, Switzerland. This article is an open access article distributed under the terms and conditions of the Creative Commons Attribution (CC BY) license (http://creativecommons.org/licenses/by/4.0/). 